\title{
Chloroform extract of Hedyotis diffusa Willd inhibits viability of human colorectal cancer cells via suppression of AKT and ERK signaling pathways
}

\author{
ZHAOKUN YAN ${ }^{1}$, JIANYU FENG $^{1}$, JUN PENG $^{1,2}$, ZIJUN LAI $^{1}$, LING ZHANG $^{1,2}$, \\ YIYI JIN ${ }^{1}$, HONG YANG ${ }^{1}$, WUJIN CHEN $^{3}$ and JIUMAO LIN ${ }^{1,2}$ \\ ${ }^{1}$ Academy of Integrative Medicine; ${ }^{2}$ Fujian Key Laboratory of Integrative Medicine on Geriatrics, Fujian \\ University of Traditional Chinese Medicine, Minhou Shangjie, Fuzhou, Fujian 350122; ${ }^{3}$ The Affiliated People's \\ Hospital of Fujian University of Traditional Chinese Medicine, Fuzhou, Fujian 350004, P.R. China
}

Received September 4, 2016; Accepted August 1, 2017

DOI: $10.3892 / 01.2017 .7245$

\begin{abstract}
Hedyotis diffusa Willd (HDW) is a widely used traditional Chinese medicine in clinical therapy to treat various types of cancer, including colorectal cancer (CRC), but its effective polar fractions and functional mechanisms remain unclear. The aim of the present study was to determine the most effective extract of HDW and to investigate its effects on the regulation of CRC cell proliferation and apoptosis, as well as to investigate the underlying molecular mechanisms. The results demonstrated that the chloroform extract of HDW (CEHDW) exhibited the most anticancer ability. Furthermore, results of the MTT assay, colony formation, carboxyfluorescein diacetate succinimidyl ester assay and annexin V/propidium iodide staining suggested that CEHDW significantly inhibits proliferation and promotes apoptosis in the SW620 CRC cell line. Additionally, reverse transcription-polymerase chain reaction and western blot analysis demonstrated that CEHDW treatment downregulated the expression of Survivin, proliferating cell nuclear antigen, Cyclin D1, cyclin-dependent kinase 4 and B-cell lymphoma 2 (Bcl-2), and upregulated the expression of Bcl-2-associated $\mathrm{X}$ protein at the mRNA and protein levels. CEHDW also decreased the phosphorylation of protein kinase B (AKT) and extracellular-signal-regulated kinase (ERK), which indicated that the suppression of the AKT and ERK signaling pathways may be one of the underlying
\end{abstract}

Correspondence to: Dr Jiumao Lin, Academy of Integrative Medicine, Fujian University of Traditional Chinese Medicine, 1 Qiuyang Road, Minhou Shangjie, Fuzhou, Fujian 350122, P.R. China E-mail: jiumaolin@hotmail.com

Abbreviations: CRC, colorectal cancer; CEHDW, chloroform extract of Hedyotis diffusa Willd; TCM, traditional Chinese medicine; AKT, protein kinase B; ERK, extracellular-signal-regulated kinase

Key words: Hedyotis diffusa Willd, colorectal cancer, protein kinase $\mathrm{B}$, extracellular-signal-regulated kinase, proliferation, apoptosis molecular mechanisms by which CEHDW exhibited its anticancer effect. Thus, CEHDW may be a promising agent for anticancer therapy.

\section{Introduction}

Colorectal cancer (CRC) is the third most frequent type of cancer in males and the second in females, and the fourth most common cause of oncological mortality worldwide (1). Surgical resection is the major treatment for patients with CRC. However, $\sim 75 \%$ of patients with resectable metastatic CRC undergo postoperative recurrence within 18 months of surgery (2). CRC is difficult to treat due to unlimited cell proliferation and resistance to cell apoptosis. Therefore, chemotherapy which executes an antitumor effect through decreasing cell proliferation or inducing cell apoptosis, is administered to alleviate symptoms and prolong survival (3). However, these chemotherapeutic agents exhibit significant side effects on off-target cells, including normal cells. Drug resistance, drug toxicity and conditions including anemia, leucopenia, thrombocytopenia and peripheral neuropathy limit the effectiveness of these treatments, increasing the requirement for the development of novel therapeutic approaches (4).

Traditional Chinese medicine (TCM) has been used to treat cancer for thousands of years in China. TCM combined with modern treatments may improve symptoms, enhance quality of life, prevent recurrence and metastasis, and prolong patient survival. Additionally, TCM has potential advantages in patients who are not suitable candidates for radiotherapy and chemotherapy (5). TCM involves numerous chemical compounds, and is therefore considered to be multi-component and multi-target exerting therapeutic functions in a more holistic way. Discovering naturally occurring agents is a promising approach for the treatment of cancer (6).

Hedyotis diffusa Willd (HDW) is a well-known herbal medicine, which exhibits a variety of bioactivities, including anti-inflammatory, antioxidative, immune-modulating and anticancer properties (7-9). Belonging to the Rubiaceae family of plants, HDW is widely distributed in Northeast Asia. It is used in TCM to clear away heat and toxic material $(7,8)$, 
to promote blood circulation and has long been used clinically to treat various types of cancer, including breast (10), colorectal (11) and liver (12) cancer. Our previous studies demonstrated that HDW inhibited the growth of CRC, possibly by inducing cancer cell apoptosis and inhibiting cell proliferation and tumor angiogenesis (13-17). However, HDW has a complicated chemical composition and the effectiveness of its various polar fractions remains largely unclear. In the present study, the effect of polar extracts of HDW on four human colorectal cancer cell lines, SW620, HT-29, HCT116 and HCT-8, were compared, and the potential underlying molecular mechanisms were investigated.

\section{Materials and methods}

Materials and reagents. Dulbecco's modified Eagle's medium (DMEM), RPMI-1640 medium, fetal bovine serum (FBS), penicillin-streptomycin, $0.25 \%$ trypsin-EDTA, DreamTaq Green PCR Master Mix and Pierce Bicinchoninic Acid (BCA) Protein Assay kit were purchased from Thermo Fisher Scientific, Inc. (Waltham, MA, USA). MTT was purchased from Beijing Solarbio Science and Technology Co., Ltd. (Beijing, China). Carboxyfluorescein diacetate succinimidyl ester (CFDA-SE) Cell Proliferation and Tracking kit and Annexin V-Fluorescein Isothiocyante (FITC) Apoptosis Detection kit were purchased from Nanjing KeyGen Biotech Co., Ltd. (Nanjing, China). RNAiso Plus and PrimeScript RT Reagent kit with gDNA Eraser (Perfect Real Time) was purchased from Takara Biotechnology Co., Ltd. (Dalian, China). Radio immunoprecipitation assay (RIPA) lysis buffer and blocking buffer were purchased from Beyotime Institute of Biotechnology (Haimen, China). Rabbit polyclonal antibodies against $\beta$-actin (20536-1-AP), Survivin (0508-1-AP), protein kinase B (AKT; 10176-2-AP) and extracellular-signal-regulated kinase (ERK; 16443-1-AP) were purchased from Proteintech Wuhan Sanying Biotechnology (Wuhan, China). Rabbit polyclonal antibodies against Bcl-2-associated X-protein (Bax; D220073), B-cell lymphoma 2 (Bcl-2; D160117), cyclin-dependent kinase 4 (CDK4; D220396) and proliferating cell nuclear antigen (PCNA; D120014) were purchased from Sangon Biotech Co., Ltd. (Shanghai, China). Rabbit polyclonal antibodies against Cyclin D1 (sc-753), phospho-AKT (p-AKT; sc-135650) and phospho-ERK (p-ERK; sc-16982-R) were purchased from Santa Cruz Biotechnology, Inc. (Dallas, TX, USA). Horseradish peroxidase (HRP)-conjugated goat anti-rabbit (E030120-01) was purchased from Earthox LLC (Millbrae, CA, USA). Culture flasks and plates were purchased from NEST Biotechnology Co., Ltd. (Wuxi, Jiangsu, China). All other chemicals used, unless otherwise stated, were purchased from Sigma Aldrich; Merck KGaA (Darmstadt, Germany).

Preparation of the HDW extract. HDW was purchased from the Guo Yi Tang Chinese Herbal Medicine Store (Fujian, China). Using a procedure described previously (18), $500 \mathrm{~g} \mathrm{HDW}$ was extracted. A series of solvents were applied including chloroform, petroleum ether, n-butanol and ethyl acetate resulting in the chloroform extract of HDW (CEHDW), the petroleum ether extract of HDW (PEEHDW), the n-butanol extract of HDW (NBEHDW) and the ethyl acetate extract of
HDW (EAEHDW), respectively. All extracts were separately evaporated on a rotary evaporator. Subsequently, powders of the extracts were dissolved in $100 \%$ dimethyl sulfoxide (DMSO) to a stock concentration of $100 \mathrm{mg} / \mathrm{ml}$ and stored at $-20^{\circ} \mathrm{C}$. The final concentration of DMSO in the medium for all experiments was $<0.5 \%$.

Cell culture. The human colorectal cancer cell lines SW620, HT-29, HCT116 and HCT-8 were purchased from the Cell Bank of the Chinese Academy of Sciences (Shanghai, China). SW620 and HT-29 cells were cultured in DMEM supplemented with $10 \%$ (v/v) FBS, $100 \mathrm{U} / \mathrm{ml}$ penicillin and $100 \mu \mathrm{g} / \mathrm{ml}$ streptomycin. HCT116 and HCT-8 cells were cultured in RPMI-1640 medium supplemented with $10 \%$ (v/v) FBS, $100 \mathrm{U} / \mathrm{ml}$ penicillin and $100 \mu \mathrm{g} / \mathrm{ml}$ streptomycin. All of the cell lines were cultured at $37^{\circ} \mathrm{C}$ in a humidified incubator containing $5 \% \mathrm{CO}_{2}$.

Cell viability evaluation. An MTT assay was used to assess the cell viability. SW620, HT-29, HCT116 and HCT-8 cells were incubated in 96-well plates at a density of $1 \times 10^{5}$ cells $/ \mathrm{ml}$ in $100 \mu \mathrm{l}$ culture medium for $12 \mathrm{~h}$ and treated with various concentrations $(0,150,300$ and $500 \mu \mathrm{g} / \mathrm{ml})$ of HDW extract for $24 \mathrm{~h}$ at $37^{\circ} \mathrm{C}$. In addition, SW620 cells were treated with various concentrations $(0,12.5,25,50,75$ and $100 \mu \mathrm{g} / \mathrm{ml})$ of CEHDW for $24 \mathrm{~h}$ at $37^{\circ} \mathrm{C}$ in an additional MTT assay. Subsequently, the medium was replaced with $100 \mu 1 \mathrm{MTT}$ $\left(0.5 \mathrm{mg} / \mathrm{ml}\right.$ in PBS) and cells were incubated at $37^{\circ} \mathrm{C}$. After $4 \mathrm{~h}$, the MTT solution was removed and $100 \mu \mathrm{l}$ DMSO was added to solubilize the purple-blue formazan precipitate. The resulting absorbance was measured at $570 \mathrm{~nm}$ using an ELISA reader (model ELX800; BioTek Instruments, Inc., Winooski, VT, USA).

Colony formation assay. SW620 cells were seeded into 6-well plates at a density of $3 \times 10^{5}$ cells $/ \mathrm{ml}$ in $2 \mathrm{ml}$ culture medium. Following treatment with various concentrations $(0,50$, 75 and $100 \mu \mathrm{g} / \mathrm{ml}$ ) of CEHDW for $24 \mathrm{~h}$ at $37^{\circ} \mathrm{C}$, cells were harvested and diluted with fresh medium without CEHDW, and subsequently reseeded in 6-well plates at a density of 1,000 cells/well in $2 \mathrm{ml}$. The medium was replaced with fresh medium every 4 days. After 10 days, colonies were fixed with $10 \%$ formaldehyde for $15 \mathrm{~min}$ at room temperature, stained with $0.01 \%$ crystal violet for $10 \mathrm{~min}$ at room temperature and photographed with digital camera.

CFDA-SE cell proliferation assay. The CFDA-SE probe was used to determine the cell proliferation (19). Briefly, SW620 cells were stained with $5 \mu \mathrm{M}$ CFDA-SE for $30 \mathrm{~min}$ at $37^{\circ} \mathrm{C}$ in the dark then seeded in 12 -well plates at a density of $2.5 \times 10^{5}$ cells $/ \mathrm{ml}$ in $1 \mathrm{ml}$ medium according to the manufacturer's protocol. Subsequently, cells were exposed to a series of concentrations of CEHDW for $24 \mathrm{~h}$. CFDA-SE fluorescence was detected using a FACSCaliber instrument (BD Biosciences, San Jose, CA, USA).

Analysis of apoptosis using annexin $V$ and propidium iodide (PI) double staining. SW620 cells were treated with various concentrations $(0,50,75$ and $100 \mu \mathrm{g} / \mathrm{ml})$ of CEHDW for $24 \mathrm{~h}$ at $37^{\circ} \mathrm{C}$. Cell apoptosis was determined using flow 
Table I. Primer sequences for reverse transcription-polymerase chain reaction.

\begin{tabular}{|c|c|c|}
\hline Gene & Primer sequence $\left(5^{\prime}-3^{\prime}\right)$ & Product size, bp \\
\hline Survivin & $\begin{array}{l}\text { Forward, 5'-CTGGGCTATGGGTGAGGTTC-3' } \\
\text { Reverse, 5'-CCCTAGAATCAGACAGCCGAC-3' }\end{array}$ & 686 \\
\hline PCNA & $\begin{array}{l}\text { Forward, 5'-GCTGACATGGGACACTTA-3' } \\
\text { Reverse, 5'-CTCAGGTACAAACTTGGTG-3' }\end{array}$ & 165 \\
\hline Cyclin D1 & $\begin{array}{l}\text { Forward, 5'-TGGATGCTGGAGGTCTGCGAGGAA-3' } \\
\text { Reverse, 5'-GGCTTCGATCTGCTCCTGGCAGGC-3' }\end{array}$ & 573 \\
\hline CDK4 & $\begin{array}{l}\text { Forward, 5'-GGTCAAAGATTTTGCCCAAC-3' } \\
\text { Reverse, 5'-CCGAAGTTCTTCTGCAGTCC-3' }\end{array}$ & 138 \\
\hline Bcl-2 & $\begin{array}{l}\text { Forward, 5'-CAGCTGCACCTGACGCCCTT-3' } \\
\text { Reverse, 5'-GCCTCCGTTATCCTGGATCC-3' }\end{array}$ & 231 \\
\hline Bax & $\begin{array}{l}\text { Forward, 5'-TGCTTCAGGGTTTCATCCAGG-3' } \\
\text { Reverse, 5'-TGGCAAAGTAGAAAAGGGCGA-3' }\end{array}$ & 276 \\
\hline GAPDH & $\begin{array}{l}\text { Forward, 5'-CGACCACTTTGTCAAGCTCA-3' } \\
\text { Reverse, 5'-AGGGGTCTACATGGCAACTG-3' }\end{array}$ & 228 \\
\hline
\end{tabular}

PCNA, proliferating cell nuclear antigen; CDK4, cyclin dependent kinase 4; Bcl-2, B-cell lymphoma-2; Bax, Bcl-2-associated X protein.

cytometry. Annexin V/PI staining was performed prior to analysis using a FACSCaliber instrument, according to the manufacturer's protocol. In this assay, the annexin V/PI double-negative population indicates viable cells, and the annexin V-positive/PI-negative or annexin V/PI double-positive population represents cells undergoing early or late apoptosis, respectively.

Reverse transcription-polymerase chain reaction ( $R T-P C R)$ analysis. SW620 cells were treated with various concentrations $(0,50,75$ and $100 \mu \mathrm{g} / \mathrm{ml})$ of CEHDW for $24 \mathrm{~h}$ at $37^{\circ} \mathrm{C}$. RNA from cell samples was isolated with RNAiso Plus. Oligo-dT-primed RNA ( $1 \mu \mathrm{g})$ was reverse-transcribed using PrimeScript RT Reagent kit with gDNA Eraser (Perfect Real Time), according to the manufacturer's protocol. The resultant cDNA was used to determine the amount of Survivin, PCNA, Cyclin D1, CDK4, Bcl-2 and Bax mRNA using PCR with DreamTaq Green PCR Master Mix. PCR was performed using the 3-step method, with a denaturation stage at $95^{\circ} \mathrm{C}$ for $30 \mathrm{sec}$, an annealing stage at an appropriate temperature $\left(55^{\circ} \mathrm{C}\right.$ for Survivin, CDK4, Bcl-2 and Bax, and $58^{\circ} \mathrm{C}$ for PCNA, Cyclin $\mathrm{D} 1$ and GAPDH) for $30 \mathrm{sec}$ and an extension stage at $72^{\circ} \mathrm{C}$ for $30 \mathrm{sec}$ for 30 cycles. GAPDH was used as an internal control. The primers were synthesized by Invitrogen; Thermo Fisher Scientific, Inc., and the sequences are listed in Table I.

Western blot analysis. SW620 cells were treated with various concentrations $(0,50,75$ and $100 \mu \mathrm{g} / \mathrm{ml})$ of CEHDW for $24 \mathrm{~h}$ at $37^{\circ} \mathrm{C}$. Cells were washed with PBS three times and lysed with RIPA lysis buffer containing EASYpack protease inhibitor cocktail (Roche Diagnostics, Basel, Switzerland) and PhosSTOP (Roche Diagnostics). The concentrations of resultant protein were quantified using the BCA Protein Assay kit. Proteins $(50 \mu \mathrm{g})$ were separated by SDS-PAGE and transferred onto nitrocellulose membranes (EMD Millipore
Corporation, Darmstadt, Germany). The membranes were blocked with blocking buffer for $2 \mathrm{~h}$ at room temperature and incubated with antibodies against Survivin, PCNA, Cyclin D1, CDK4, Bcl-2, Bax, AKT, ERK, p-AKT, p-ERK or $\beta$-actin (all 1:1,000 dilution) for $16 \mathrm{~h}$ at $4^{\circ} \mathrm{C}$, and then washed three times with Tris-buffered saline with Tween-20 (TBST), respectively. Subsequently, the membranes were incubated with HRP-conjugated goat anti-rabbit secondary antibodies for $1 \mathrm{~h}$ at room temperature. Cells were washed again in TBST and membranes were visualized using a BeyoECL Plus instrument. Image Lab ${ }^{\mathrm{TM}}$ software (version 3.0; Beyotime Institute of Biotechnology) was used for densitometric analysis and quantification of western blots.

Statistical analysis. Data were analyzed using the SPSS package for Windows (version 17.0; SPSS Inc., Chicago, IL, USA) using one-way analysis of variance. Fisher's least significant difference and Dunnett's test were used as post-hoc tests. $\mathrm{P}<0.05$ was considered to indicate a statistically significant difference.

\section{Results}

CEHDW exhibits the most potent inhibitory effect on the viability of colorectal cancer cells. The inhibitory effects of CEHDW, PEEHDW, NBEHDW and EAEHDW on the viability of the CRC cell lines were determined using an MTT assay. As presented in Fig. 1A-D, the four cell lines were exposed to various concentrations of the four extracts for 24 or 48 h. CEHDW exhibited the most antitumor activity in all cell lines. NBEHDW exhibited no significant inhibitory effects. PEEHDW decreased the cell viability of SW620 and HT-29 cells, but exhibited a limited effect on HCT116 and HCT-8 cells. Similarly, EAEHDW significantly inhibited the viability of SW620, HT-29 and HCT116 cells, but not HCT-8 cells. 

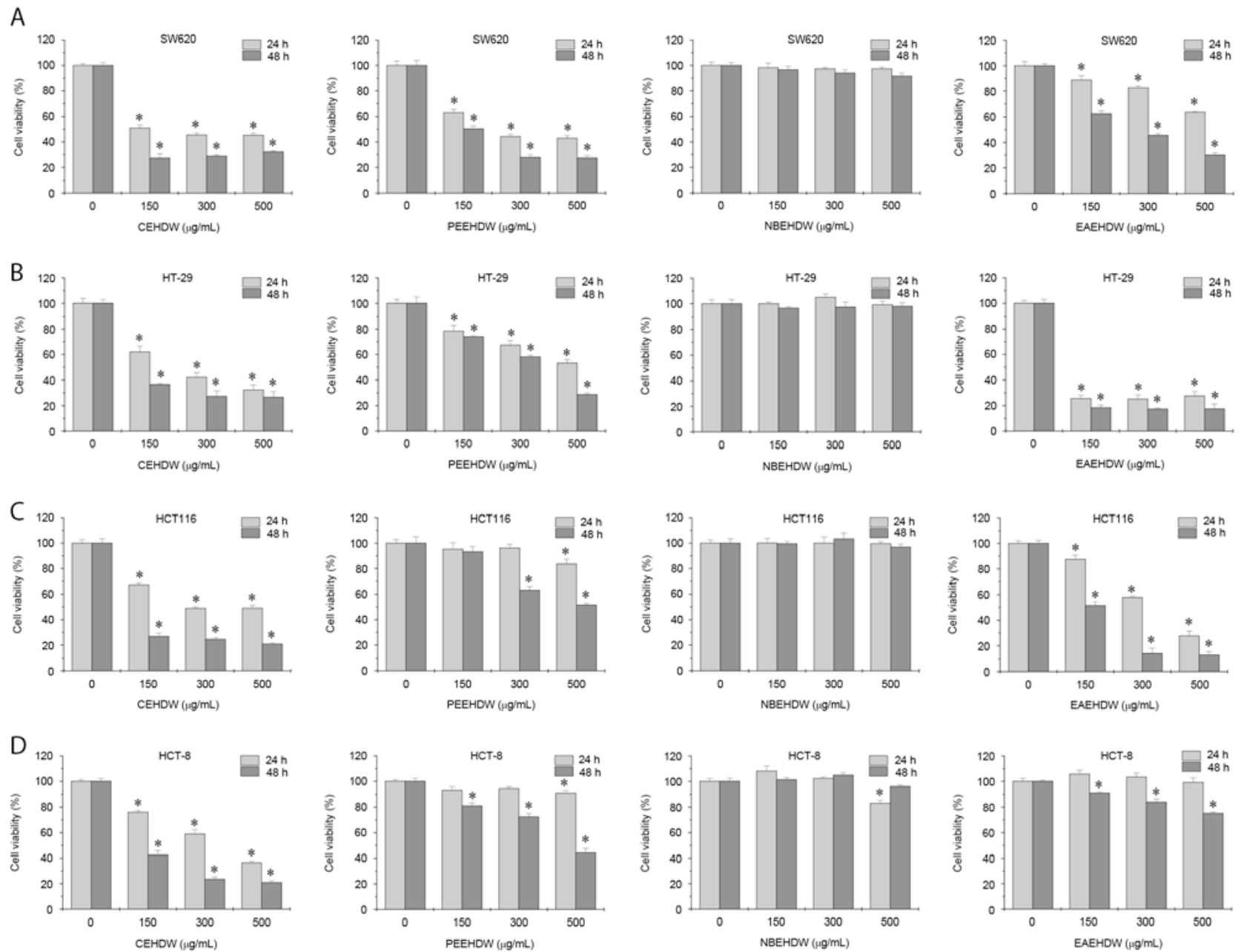

Figure 1. Effect of polar fractions of HDW on viability of human colorectal cancer cells. (A) SW620, (B) HT-29, (C) HCT116 and (D) HCT-8 cells were treated with CEHDW, PEEHDW, NBEHDW or EAEHDW for 24 or $48 \mathrm{~h}$. Cell viability was determined using an MTT assay. The data were normalized to the viability of the untreated control cells $(100 \%)$. Data are expressed as the mean \pm standard deviation from at least three independent experiments. ${ }^{*} \mathrm{P}<0.05$ vs. untreated control cells. HDW, Hedyotis diffusa Willd; CEHDW, chloroform extract of Hedyotis diffusa Willd; PEEHDW, petroleum ether extract of Hedyotis diffusa Willd; NBEHDW, n-butanol extract of Hedyotis diffusa Willd; EAEHDW, ethyl acetate extract of Hedyotis diffusa Willd.

CEHDW inhibits the viability of SW620 cells. Following CEHDW treatment, SW620 demonstrated the most drug sensitivity as presented in Fig. 1A. Therefore, the SW620 cell line was selected for further study. In order to evaluate the effect of CEHDW on SW620 cells, viability was determined using an MTT assay. Treatment with between 12.5 and $100 \mu \mathrm{g} / \mathrm{ml}$ CEHDW for $24 \mathrm{~h}$ decreased cell viability by between 7.3 and $60.23 \%$, when compared with untreated cells (Fig. 2A). To observe the effects of CEHDW on cell morphology, the appearance of the treated and untreated SW620 monolayers were compared using phase-contrast microscopy. Untreated SW620 cells appeared as a crowded and disorganized monolayer after $24 \mathrm{~h}$ (Fig. 2B). The cell density was decreased in the confluent monolayers that had been treated with CEHDW, with the attached cells exhibiting a round appearance (Fig. 2B). To estimate the effect of CEHDW on cell survival, SW620 cells were examined by performing the colony formation assay. The number of colonies was decreased following CEHDW treatment, and almost no colonies were observed following treatment with CEHDW at concentrations of 50, 75 and $100 \mu \mathrm{g} / \mathrm{ml}$ for $24 \mathrm{~h}$ (Fig. 2C). To determine the effect of CEHDW on cell proliferation, a CFDA-SE assay was performed. As presented in Fig. 2D and E, the ratio of fluorescence intensity of cells significantly increased following treatment with CEHDW $(50,75$ and $100 \mu \mathrm{g} / \mathrm{ml})$ for $24 \mathrm{~h}$ was $1.73,2.27$ and 2.77 , respectively, compared with that of the control group. These results suggest that CEHDW is potent in suppressing the proliferation of SW620 cells.

CEHDW promotes apoptosis of SW620 cells. In order to investigate the underlying molecular mechanism of the proliferation suppressing activity of CEHDW, its effect on apoptosis in SW620 cells was assessed using annexin V/PI staining followed by FACS analysis. As presented in Fig. 3A and B, the proportion of cells undergoing either early apoptosis or late apoptosis following treatment with $0,50,75$ and $100 \mu \mathrm{g} / \mathrm{ml}$ CEHDW was $6.58,16.86,28.75$ and $79.47 \%$, respectively, suggesting that CEHDW treatment induces apoptosis in SW620 cells in a dose-dependent manner.

CEHDW regulates the expression of Survivin, PCNA, Cyclin D1, CDK4, Bcl-2 and Bax in SW620 cells. To further explore the underlying molecular mechanism of the proliferation inhibition effect of CEHDW, RT-PCR and western blot analysis 
A

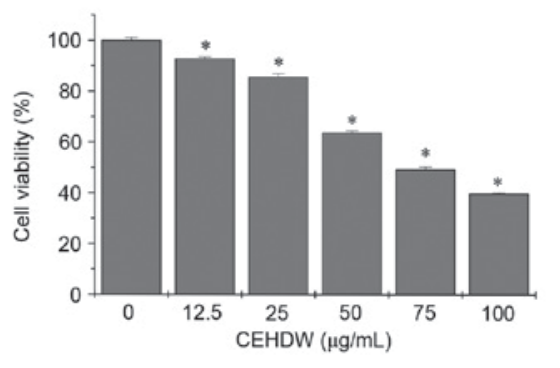

B

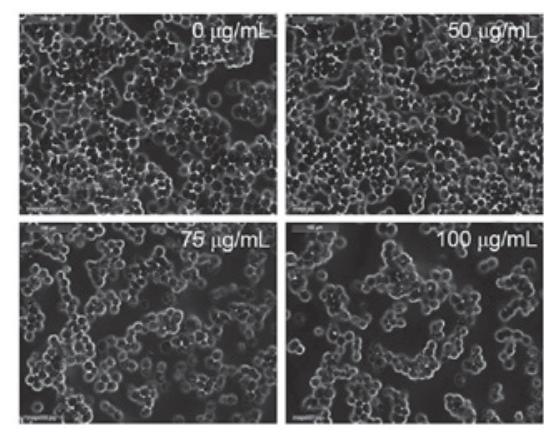

C

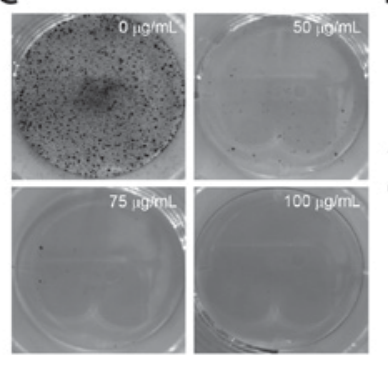

D

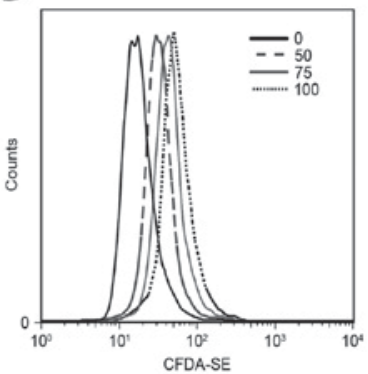

E

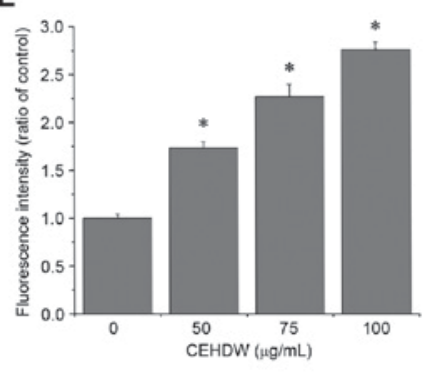

Figure 2. CEHDW treatment suppresses viability of SW620 cells. SW620 cells were treated with the indicated concentrations of CEHDW for 24 h. (A) Cell viability was determined using an MTT assay. The data were normalized to the viability of the untreated control cells (100\%). Data are expressed as the mean \pm standard deviation from at least three independent experiments. ${ }^{*} \mathrm{P}<0.05$ vs. untreated control cells. (B) Morphological changes were observed using phase-contrast microscopy. Images were captured at a magnification of x200 and are representative of three independent experiments. (C) Cell survival was determined using a colony formation assay. Images are representative of three independent experiments. (D) The proliferation of SW620 cells was determined using a CFDA-SE assay, and the proliferation was calculated by determining the alterations in fluorescence following CEHDW treatments for $24 \mathrm{~h}$. (E) The alterations in fluorescence intensity are represented relative to that of the control. Data are expressed as the mean \pm standard deviation from at least three independent experiments. ${ }^{*}<<0.05$ vs. untreated control cells. CEHDW, chloroform extract of Hedyotis diffusa Willd; CFDA-SE, carboxyfluoroscein diacetate succinimidyl ester.
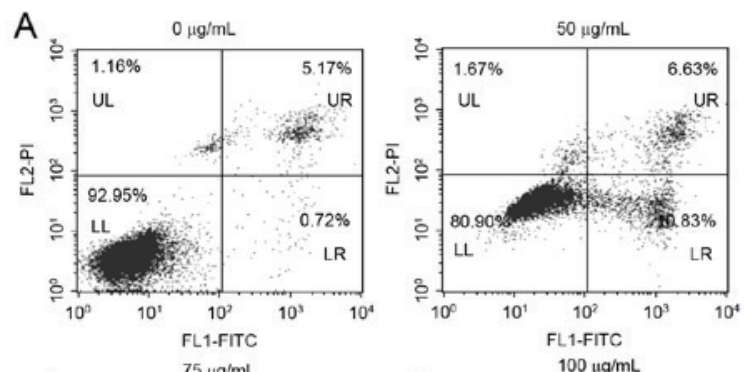

B
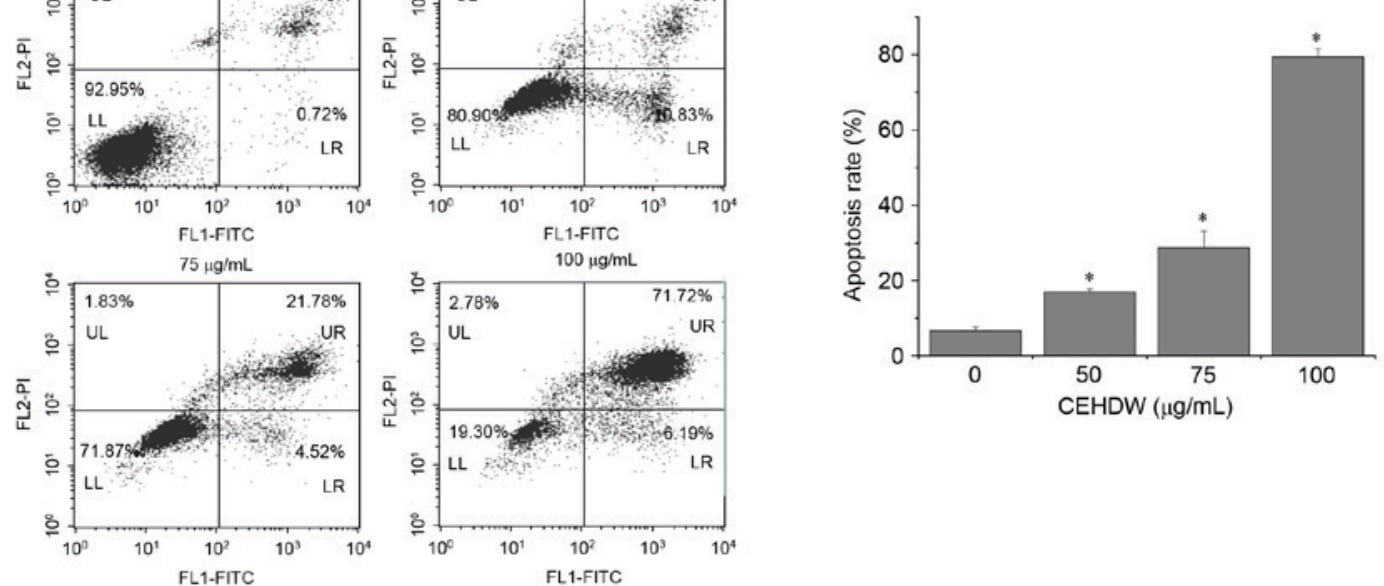

Figure 3. CEHDW treatment induces apoptosis of SW620 cells. (A) SW620 cells were treated with various concentrations of CEHDW for $24 \mathrm{~h}$, and cells were collected and stained with annexin V/PI followed by FACS analysis. (B) Quantification of FACS analysis. Data are expressed as the mean \pm standard deviation from at least three independent experiments. "P<0.05 vs. untreated control cells. CEHDW, chloroform extract of Hedyotis diffusa Willd; PI, propidium iodide; UL, necrotic cells; UR, later apoptotic cells; LL, surviving cells; LR, early apoptotic cells.

were performed to determine the expression of Survivin, PCNA, Cyclin D1, CDK4, Bcl-2 and Bax at the mRNA and protein levels. RT-PCR results revealed that CEHDW treatment decreased mRNA expression of the pro-proliferative PCNA, Cyclin D1 and CDK4 and anti-apoptotic Bcl-2 and Survivin, while also increasing expression of the pro-apoptotic Bax (Fig. 4A and B). The protein expression patterns of Survivin,
PCNA, Cyclin D1, CDK4, Bcl-2 and Bax were similar to that observed for the respective mRNA (Fig. 4C and D).

CEHDW inhibits AKT and ERK phosphorylation in SW620 cells. To gain further insight into the association between CEHDW and the proliferation and apoptosis of CRC cells, AKT and ERK signaling molecules were investigated. As 


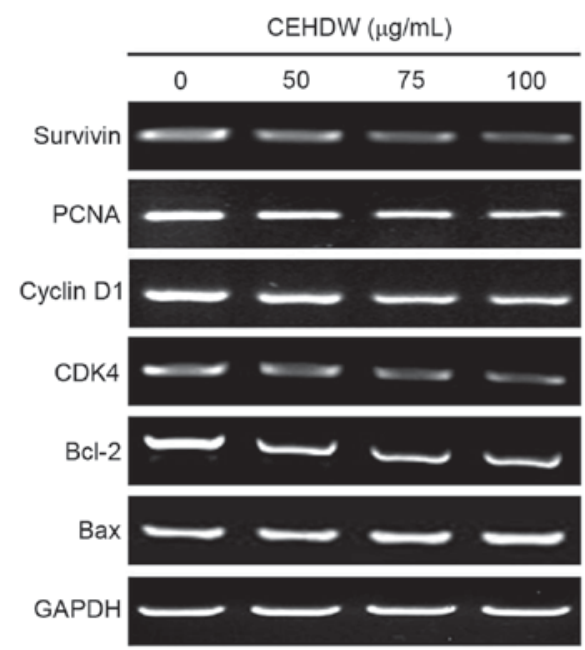

$\mathrm{C}$

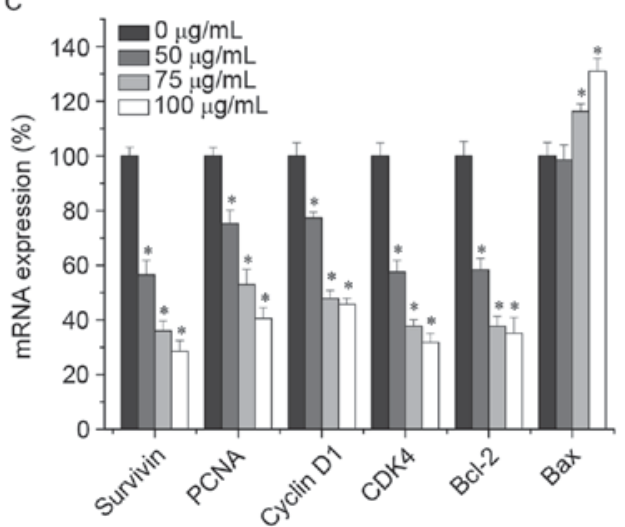

B

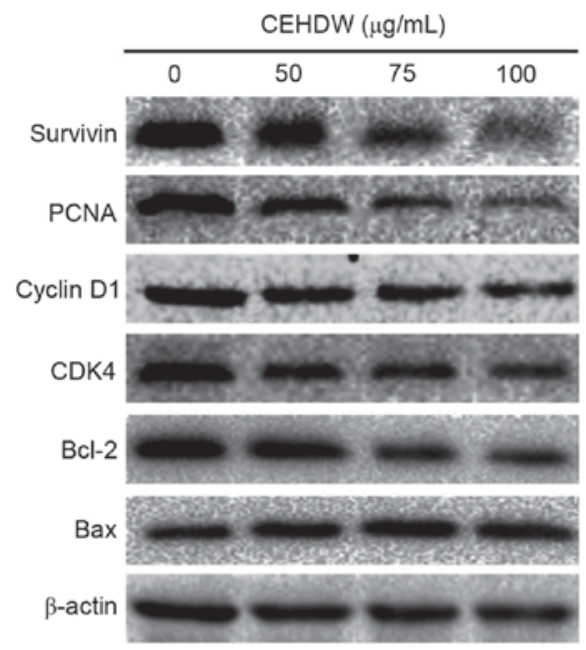

D

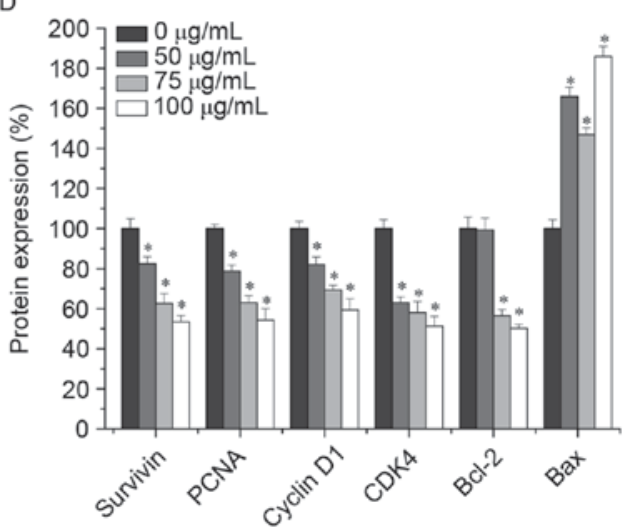

Figure 4. CEHDW treatment regulates expression of Survivin, PCNA, cyclin D1, CDK4, Bcl-2 and Bax in SW620 cells. Cells were treated with various concentrations of CEHDW for $24 \mathrm{~h}$. (A) mRNA expression and (B) protein expression levels of Survivin, PCNA, Cyclin D1, CDK4, Bcl-2 and Bax were evaluated by RT-PCR and Western blot analysis, respectively. GAPDH and $\beta$-actin were used as the internal controls for the RT-PCR and western blotting, respectively. Densitometric analysis. The data were normalized to the mean (C) mRNA or (D) protein expression of untreated control (100\%). "P<0.05 vs. internal controls. CEHDW, chloroform extract of Hedyotis diffusa Willd; PCNA, proliferating cell nuclear antigen; CDK4, cyclin-dependent kinase 4; Bcl-2, B-cell lymphoma 2; Bax, Bcl-2-associated X protein; RT-PCR, reverse transcription-polymerase chain reaction.

A

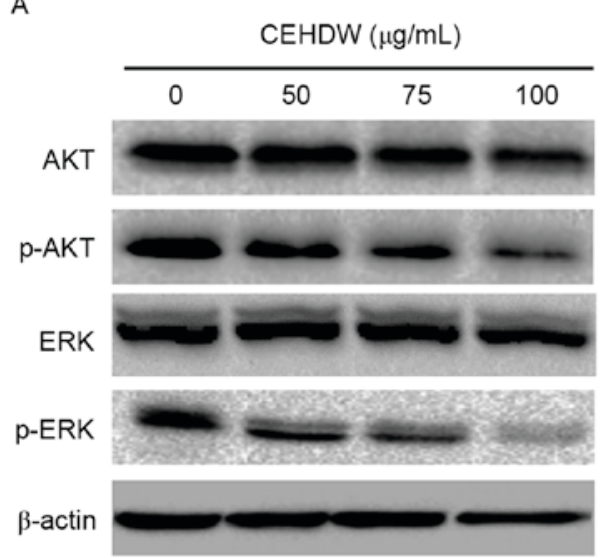

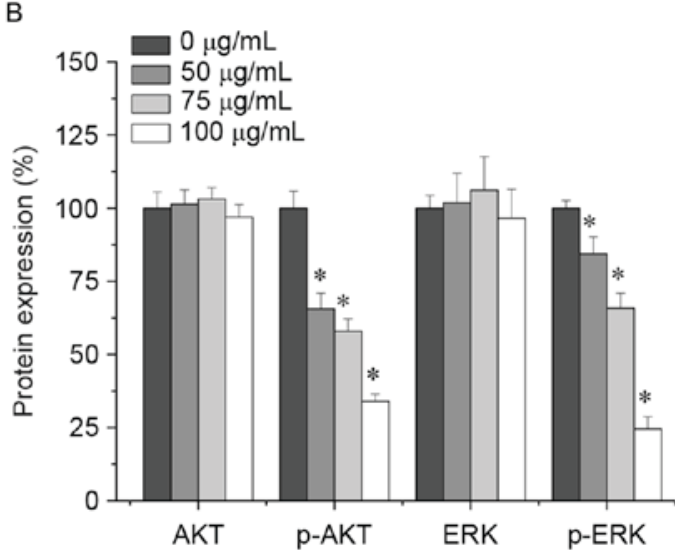

Figure 5. CEHDW treatment inhibits phosphorylation of AKT and ERK in SW620 cells. (A) The levels of AKT and ERK phosphorylation in SW620 cells were determined by western blotting. Images are representative of three independent experiments. (B) Densitometric analysis. The data were normalized to the mean protein expression of untreated control (100\%). " $\mathrm{P}<0.05$ vs. untreated control cells. CEHDW, chloroform extract of Hedyotis diffusa Willd; RT-PCR, reverse transcription-polymerase chain reaction; AKT, protein kinase B; ERK, extracellular-signal-regulated kinase; p-, phospho-.

presented in Fig. 5A and B, AKT and ERK phosphorylation were decreased following treatment with 50,75 and $100 \mu \mathrm{g} / \mathrm{ml}$
CEHDW for $24 \mathrm{~h}$, indicating that the AKT and ERK signaling pathways may be involved in CRC cell apoptosis. 


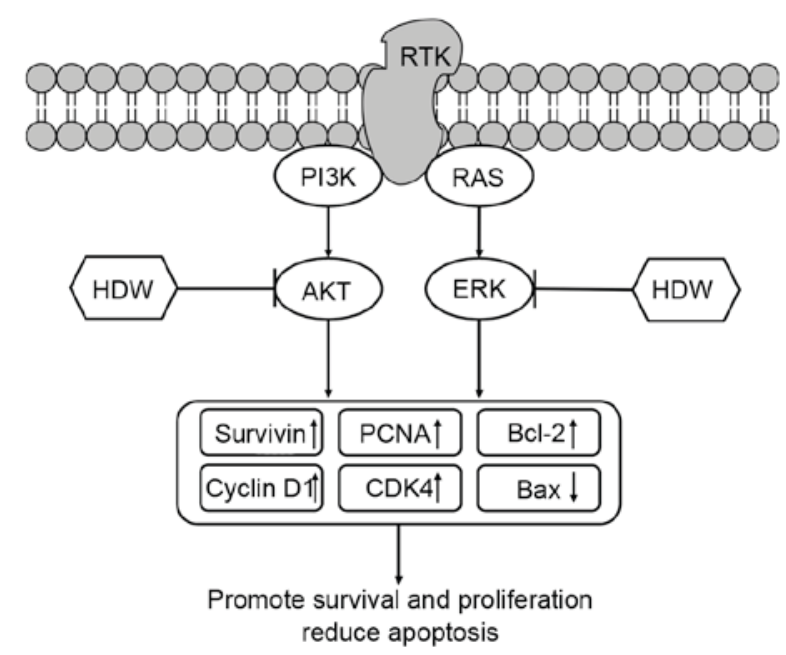

Figure 6. Schematic diagram of the potential underlying molecular mechanisms of CEHDW inhibiting proliferation of SW620 cells. HDW inhibits AKT and ERK phosphorylation, which subsequently upregulates Survivin, PCNA, Cyclin D1, CDK4, Bcl-2 and downregulates Bax, promoting survival and proliferation and decreasing apoptosis of SW620 cells. CEHDW, chloroform extract of Hedyotis diffusa Willd; HDW, Hedyotis diffusa Willd; AKT, protein kinase B; ERK, extracellular-signal-regulated kinase; PCNA, proliferating cell nuclear antigen; CDK4, cyclin-dependent kinase 4; BCL-2, B-cell lymphoma-2; BAX, Bcl-2-associated X protein; PI3K, phosphoinositide 3-kinase; RTK, receptor tyrosine kinase.

\section{Discussion}

As a multi-component herb, the active ingredients of HDW are distinct between various extracts due to different polarity. Ursolic acid (UA) and oleanolic acid (OA) are hypothesized to be the major active ingredients of HDW and have been demonstrated to possess anticancer activity (20-24). It has been reported that, among CEHDW, EAEHDW and NBEHDW, the highest levels of UA or OA were observed in CEHDW, which may explain the discrepancy in the therapeutic effect of different extracts (25). To verify this hypothesis, in the present study various organic solvents were used for HDW extracts, and their anticancer effects were compared. MTT assays revealed that CEHDW exhibited the most potent anticancer activity in the CRC cell lines, but whether this was due to the higher content of UA or OA remains unknown and requires further investigation.

The unlimited proliferation and apoptosis resistance of cancer cells facilitates the continuous growth and progression of tumors (26). The current clinical therapies including resection and radio- or chemotherapies aim to remove the majority of solid tumors and to suppress proliferation of the remaining cancer cells, and therefore cure cancer. However, they often fail with recurrence, metastasis, drug resistance and other side effects occurring in patients. The inhibition of proliferation and promotion of apoptosis remain the standard approach of anticancer therapy. For improved therapeutic effect and higher quality of life, multi-target therapy should be emphasized, and the majority of TCMs including HDW exhibit advantages in this respect $(27,28)$. HDW has been reported to be clinically effective with few side effects (5). In the present study using MTT assays, colony formation assays, CFDA-SE and annexin V/PI staining, it was established that the anticancer effect of CEHDW is primarily achieved through the inhibition of proliferation and promotion of apoptosis.

Numerous disordered genes and aberrant activation of signaling pathways regulate the growth of cancer. For instance, Survivin is a protein that is able to block apoptosis to prevent cell death and prolong cell survival (29). PCNA is a specific marker of cell division associated with DNA polymerase, synthesized shortly prior to the S-phase of the cell cycle (30). Cyclin D1 regulates the cell proliferation through the phosphorylation and inhibition of pocket proteins by forming an active complex with CDK4 (31). Apoptosis is largely controlled by Bcl-2 family members, including Bcl-2 and Bax. In particular, the ERK and AKT signaling pathways are involved in the regulation of CRC cell apoptosis $(32,33)$; therefore, a rebalance of cell apoptosis and proliferation by the regulation of AKT and ERK signaling pathways and the expression of other associated genes is a promising target for the development of anticancer therapies. In the present study, using CRC SW620 cells, it was identified that CEHDW decreased the phosphorylation activation of AKT and ERK, decreased the expression of Bcl-2, Survivin, PCNA, Cyclin D1 and CDK4, and increased the expression of Bax.

The results of the present study demonstrate that CEHDW exhibits a potent inhibitory effect on CRC cell growth, which is mediated by its pro-apoptotic and anti-proliferative activity. Furthermore, the effect of CEHDW is mediated through the AKT and ERK signaling pathways (Fig. 6). These results provide a strong scientific foundation for the development of novel anticancer agents from the bioactive ingredients in CEHDW. HDW may execute anticancer effects by regulating multiple targets and signaling pathways. Elucidation of the complete underlying molecular mechanism requires further in vitro and in vivo investigation.

\section{Acknowledgements}

The present study was supported by the Research Fund for the Doctoral Program of Higher Education of China (grant no. 20133519110003), Project Funding for the Training of Young and Middle-aged Backbone Personnel of Fujian Provincial Health and Family Planning Commission (grant no. 2016-ZQN-67) and the Developmental Fund of Chen Keji Integrative Medicine (grant nos. CKJ2014013 and CKJ2015007).

\section{References}

1. Torre LA, Bray F, Siegel RL, Ferlay J, Lortet-Tieulent J and Jemal A: Global cancer statistics, 2012. CA Cancer J Clin 65: 87-108, 2015

2. McQuade RM, Bornstein JC and Nurgali K: Anti-colorectal cancer chemotherapy-induced diarrhoea: Current treatments and side-effects. Int J Clin Med 05: 393-406, 2014.

3. Colorectal cancer facts and figures 2014-2016. American Cancer Society, Atlanta, 2014.

4. Sun Y, Zhao H, Guo Y, Lin F, Tang L, Yao Y and Abba ML: Clinical study of combining chemotherapy of oxaliplatin or 5-Fluorouracil/Leucovorin with Hydroxycamptothecine for advanced colorectal cancer. Clin Oncol Cancer Res 6: 117-123, 2009.

5. Liu J, Wang S, Zhang Y, Fan HT and Lin HS: Traditional Chinese medicine and cancer: History, present situation, and development. Thorac Cancer 6: 561-569, 2015. 
6. Zhuang Q, Hong F, Shen A, Zheng L, Zeng J, Lin W, Chen Y, Sferra TJ, Hong Z and Peng J: Pien Tze Huang inhibits tumor cell proliferation and promotes apoptosis via suppressing the STAT3 pathway in a colorectal cancer mouse model. Int J Oncol 40: $1569-1574,2012$.

7. Chen Y, Lin Y, Li Y and Li C: Total flavonoids of Hedyotis diffusa Willd inhibit inflammatory responses in LPS-activated macrophages via suppression of the NF-kappaB and MAPK signaling pathways. Exp Ther Med 11: 1116-1122, 2016.

8. Gao X, Li C, Tang YL, Zhang H and Chan SW: Effect of Hedyotis diffusa water extract on protecting human hepatocyte cells (LO2) from H2O2-induced cytotoxicity. Pharm Biol 54: $1148-1155,2016$.

9. Kuo YJ, Lin JP, Hsiao YT, Chou GL, Tsai YH, Chiang SY, Lin JG and Chung JG: Ethanol extract of hedyotis diffusa Willd affects immune responses in normal Balb/c mice in vivo. In Vivo 29: 453-460, 2015

10. Yeh YC, Chen HY, Yang SH, Lin YH, Chiu JH, Lin YH and Chen JL: Hedyotis diffusa combined with scutellaria barbata are the core treatment of Chinese herbal medicine used for breast cancer patients: A population-based study. Evid Based Complement Alternat Med 2014: 202378, 2014.

11. Chao TH, Fu PK, Chang CH, Chang SN, Chiahung Mao F and Lin $\mathrm{CH}$; Evidence-based Chinese medicine research group: Prescription patterns of Chinese herbal products for post-surgery colon cancer patients in Taiwan. J Ethnopharmacol 155: 702-708, 2014.

12. Lee HZ, Bau DT, Kuo CL, Tsai RY, Chen YC and Chang YH: Clarification of the phenotypic characteristics and anti-tumor activity of Hedyotis diffusa. Am J Chin Med 39: 201-213, 2011.

13. Lin J, Chen Y, Wei L, Chen X, Xu W, Hong Z, Sferra TJ and Peng J: Hedyotis Diffusa Willd extract induces apoptosis via activation of the mitochondrion-dependent pathway in human colon carcinoma cells. Int J Oncol 37: 1331-1338, 2010.

14. Lin J, Li Q, Chen H, Lin H, Lai Z and Peng J: Hedyotis diffusa Willd. extract suppresses proliferation and induces apoptosis via IL-6-inducible STAT3 pathway inactivation in human colorecta cancer cells. Oncol Lett 9: 1962-1970, 2015.

15. Lin J, Wei L, Shen A, Cai Q, Xu W, Li H, Zhan Y, Hong Z and Peng J: Hedyotis diffusa Willd extract suppresses Sonic hedgehog signaling leading to the inhibition of colorectal cancer angiogenesis. Int J Oncol 42: 651-656, 2013.

16. Lin J, Wei L, Xu W, Hong Z, Liu X and Peng J: Effect of hedyotis diffusa Willd extract on tumor angiogenesis. Mol Med Rep 4: 1283-1288, 2011.

17. Lin M, Lin J, Wei L, Xu W, Hong Z, Cai Q, Peng J and Zhu D: Hedyotis diffusa Willd extract inhibits HT-29 cell proliferation via cell cycle arrest. Exp Ther Med 4: 307-310, 2012.

18. Zhang L, Cai Q, Lin J, Fang Y, Zhan Y, Shen A, Wei L, Wang L and Peng J: Chloroform fraction of Scutellaria barbata D. Don promotes apoptosis and suppresses proliferation in human colon cancer cells. Mol Med Rep 9: 701-706, 2014.

19. Zhong ZF, Tan W, Wang SP, Qiang WA and Wang YT: Anti-proliferative activity and cell cycle arrest induced by evodiamine on paclitaxel-sensitive and -resistant human ovarian cancer cells. Sci Rep 5: 16415, 2015.
20. Furtado RA, Rodrigues EP, Araujo FR, Oliveira WL, Furtado MA, Castro MB, Cunha WR and Tavares DC: Ursolic acid and oleanolic acid suppress preneoplastic lesions induced by 1,2-dimethylhydrazine in rat colon. Toxicol Pathol 36: 576-580, 2008.

21. Li J, Guo WJ and Yang QY: Effects of ursolic acid and oleanolic acid on human colon carcinoma cell line HCT15. World J Gastroenterol 8: 493-495, 2002.

22. Lin J, Chen Y, Wei L, Shen A, Sferra TJ, Hong Z and Peng J: Ursolic acid promotes colorectal cancer cell apoptosis and inhibits cell proliferation via modulation of multiple signaling pathways. Int J Oncol 43: 1235-1243, 2013.

23. Prasad S, Yadav VR, Sung B, Reuter S, Kannappan R, Deorukhkar A, Diagaradjane P, Wei C, Baladandayuthapani V, Krishnan S, et al: Ursolic acid inhibits growth and metastasis of human colorectal cancer in an orthotopic nude mouse model by targeting multiple cell signaling pathways: Chemosensitization with capecitabine. Clin Cancer Res 18: 4942-4953, 2012.

24. Kassi E, Papoutsi Z, Pratsinis H, Aligiannis N, Manoussakis M and Moutsatsou P: Ursolic acid, a naturally occurring triterpenoid, demonstrates anticancer activity on human prostate cancer cells. J Cancer Res Clin Oncol 133: 493-500, 2007.

25. Wang L, Chen D, Lin J and Peng J: Analysis the difference chemical constituents among the different solvent extracts from Hedyotis Diffusa Willd. Fujian Analysis \& Testing: 8-12, 2015. (In Chinese)

26. Hanahan D and Weinberg RA: Hallmarks of cancer: The next generation. Cell 144: 646-674, 2011.

27. Wang X, Feng Y, Wang N, Cheung F, Tan HY, Zhong S, Li C and Kobayashi S: Chinese medicines induce cell death: The molecular and cellular mechanisms for cancer therapy. Biomed Res Int 2014: 530342, 2014.

28. Li-Weber M: Targeting apoptosis pathways in cancer by Chinese medicine. Cancer Lett 332: 304-312, 2013.

29. Casati C, Dalerba P, Rivoltini L, Gallino G, Deho P, Rini F, Belli F, Mezzanzanica D, Costa A, Andreola S, et al: The apoptosis inhibitor protein survivin induces tumor-specific CD8+ and CD4+ T cells in colorectal cancer patients. Cancer Res 63: 4507-4515, 2003

30. Guzinska-Ustymowicz K, Pryczynicz A, Kemona A and Czyzewska J: Correlation between proliferation markers: PCNA, Ki-67, MCM-2 and antiapoptotic protein Bcl-2 in colorectal cancer. Anticancer Res 29: 3049-3052, 2009.

31. Muntean AG, Pang L, Poncz M, Dowdy SF, Blobel GA and Crispino JD: Cyclin D-Cdk4 is regulated by GATA-1 and required for megakaryocyte growth and polyploidization. Blood 109: 5199-5207, 2007.

32. Ye Q, Cai W, Zheng Y, Evers BM and She QB: ERK and AKT signaling cooperate to translationally regulate survivin expression for metastatic progression of colorectal cancer. Oncogene 33: 1828-1839, 2014

33. Feng M, Li J, Wang J, Ma C, Jiao Y, Wang Y, Zhang J, Sun Q, Ju Y, Gao L, et al: High glucose increases LPS-induced DC apoptosis through modulation of ERK1/2, AKT and Bax/Bcl-2. BMC Gastroenterol 14: 98, 2014 